\title{
Modelagem de algoritmo para sistema de informação ambiental de gerenciamento de resíduos de construção e demolição
}

Os Resíduos de Construção e Demolição (RCD) ocasionam um grande impacto negativo ao meio ambiente em decorrência de manejo inadequado em obras civis. Dessa forma, necessita-se de uma maior quantidade de matérias-primas em função das perdas ocorridas nas construções civis, tornando imperioso a redução aos impactos ao meio ambiente. Portanto, a informatização e sistematização de processos e registros operacionais em obras é relevante no gerenciamento de resíduos de construção. Nesse trabalho, o objetivo é demonstrar um modelo de algoritmo computacional para a criação de um sistema de gerenciamento de resíduos de construção e demolição civil direcionado às empresas de pequeno porte, baseado na linguagem de modelagem gráfica de sistema com orientação a objetos. Temse a finalidade de alcançar a redução, a minimização, o reaproveitamento, a reciclagem e a destinação final adequada para os resíduos produzidos em obras de civis, observando os normativos legais e as práticas de sustentabilidade. A metodologia aplicada foi a observação direta em canteiros de obras residenciais, comerciais e edifícios de múltiplos pavimentos, com identificação e catalogação dos processos executivos nas etapas construtivas. Aplicou-se também a metodologia de revisão bibliográfica, publicações acadêmicas especializadas, metodologia de pesquisa documental em planilhas orçamentárias e memoriais descritivos de obras para subsidiar as informações na modelagem do sistema. Tem-se como resultado e discussão um modelo de algoritmo computacional gráfico de sistema de gerenciamento de resíduo de construção e demolição. Esse trabalho tem proposição para a área acadêmica, a área de tecnologia da informação e principalmente para o campo da sustentabilidade em obras civis no que concerne o manejo dos Resíduos de Construção e Demolição.

Palavras-chave: Resíduos; Construção; Sustentabilidade; Algoritmo computacional.

\section{Algorithm modeling for construction and demolition waste management environmental information system}

\begin{abstract}
Construction and Demolition Waste (RCD) has a major negative impact on the environment due to improper handling in civil works. Thus, a greater amount of raw materials is required due to losses in civil construction, making it imperative to reduce environmental impacts. Therefore, computerization and systematization of processes and operational records in works is relevant in construction waste management. In this paper, the objective is to demonstrate a computational algorithm model for the creation of a construction and civil demolition waste management system for small businesses, based on the object oriented system graphical modeling language. It aims to achieve the reduction, minimization, reuse, recycling and proper disposal of waste produced in civil works, observing the legal regulations and sustainability practices. The applied methodology was the direct observation in construction sites of residential, commercial and multi-storey buildings, with identification and cataloging of the executive processes in the construction stages. We also applied the literature review methodology, specialized academic publications, documentary research methodology in budget spreadsheets and descriptive memorials of works to support the information in the system modeling. The result and discussion are a graphical computational algorithm model of construction and demolition waste management system. This work has a proposition for the academic area, the information technology area and especially for the field of sustainability in civil works regarding the management of Construction and Demolition Waste.
\end{abstract}

Keywords: Waste; Construction; Sustainability; Computational algorithm.

Topic: Tecnologia, Modelagem e Geoprocessamentos

Reviewed anonymously in the process of blind peer.
Received: $18 / 10 / 2018$

Approved: 24/12/2018
Referencing this:

SOUSA, J. C.. Modelagem de algoritmo para sistema de informação ambiental de gerenciamento de resíduos de construção e demolição. Nature and Conservation, v.11, n.2, p.41-55, 2018. DOI: http://doi.org/10.6008/CBPC2318-2881.2018.002.0005 


\section{INTRODUÇÃO}

A Construção Civil corresponde a uma parcela significativa de todas as riquezas que são produzidas no país. Desse modo, tornou-se uma cadeia produtiva com alta empregabilidade; consequentemente, grande consumidora de recursos naturais, demandando elevada quantidade de matéria prima em comparação com outros setores de base da economia nacional.

Dos materiais requeridos pela construção civil, geram-se resíduos, que podem estar associados à má qualidade de projetos de engenharia e à gestão inadequada no canteiro de obras. Por conseguinte, o correto manuseio de Resíduos de Construção e Demolição (RCD) é de fundamental importância para o correspondente aspecto ambiental, econômico e social dessa atividade empresarial.

$\mathrm{Na}$ concepção de projetos de engenharia civil ocorrem os dimensionamentos de insumos desalinhados com o efetivo real da obra, geralmente ocasionando sobredimensionamento de material, e na execução das obras ocorrem perdas pelo uso de técnicas não apropriadas de construção. Esses procedimentos geram prejuízos econômicos às construtoras, maximizam os custos da obra e provoca danos ao meio ambiente devido a manipulação inapropriada dos RCDs.

Em um cenário de mercado competitivo, a boa gestão no canteiro de obras é fator imprescindível à sobrevivência econômica da organização empresarial. Alia-se a essa competitividade o crescimento da responsabilidade no cumprimento da legislação ambiental, seja demandado pela sociedade, seja pelos órgãos públicos de regulamentação e fiscalização ou pela necessidade de mudança no padrão de consumo.

Dessa forma, as prestadoras de serviços de obras civis devem desenvolver gestão eficiente, tornando-a habilitada para o desenvolvimento das atividades de forma exitosa atendendo a legislação correlata ao tema e as demandas socioambientais. NesSe aspecto, o desenvolvimento de novas tecnologias e novos modelos construtivos com vistas a reduzir, reutilizar, reciclar (3Rs) e dar uma adequada destinação de resíduos de construção e demolição geram ativos intangíveis importantes na organização empresarial. Destacam-se as boas práticas de gestão de insumos de obras, associadas ao uso da tecnologia da informação evitando-se o impacto ambiental dos RCDs.

O processo de gerenciamento de RCD gera fluxo de informações e controles que podem ser facilitados por meio da sistematização e automatização de processos e registros com o auxílio da informática, objetivando a racionalização dos materiais associados às devidas etapas construtivas e serviços de obras. A Tecnologia da Informação e Comunicação (TIC) torna-se ferramenta imprescindível na consecução da sustentabilidade e menor custo dos serviços de engenharia, auxiliando adequadamente no processo construtivo. Assim sendo, os modelos produtivos antigos devem ser superados, e adotado novas metodologia tecnológicas de construção.

No que se refere ao desenvolvimento tecnológico, a aplicação de software ou programas de informática é base em todas as áreas do conhecimento na busca pelo resultado esperado, não sendo diferente na construção civil. Assim sendo o desenvolvimento de sistemas informatizados perpassa necessariamente pela fase de criação de algoritmo computacional. 
O algoritmo computacional é o estabelecimento de regras determinadas e definidas, atendendo aos requisitos de um problema específico através de uma sequência lógica. Cabendo a interpretação dessas regras ao computador. Diante do panorama exposto, o presente trabalho propõe um modelo de algoritmo computacional para um sistema de gerenciamento de resíduo de construção e demolição, direcionado às empresas de pequeno porte, destinado a auxiliar na prevenção qualitativa e quantitativa de materiais, observando as normas regulamentadoras sobre o tema.

\section{REVISÃO TEÓRICA}

A estruturação do tema que integra o referencial teórico está composto de breve histórico da construção civil como fator de desenvolvimento econômico, a importância da sustentabilidade ambiental em obras civis e a redução de resíduos. O conceito de sustentabilidade e RCD abrange os normativos legais, enfocando a importância do cumprimento da legislação de modo a evitar ocorrências legais e impositivas de paralisação da edificação.

Enfatiza a importância da implantação e execução do Plano de Gerenciamento de RCD, e a economia gerada na obra pelas práticas de redução e minimização de resíduos, a conceituação de gestão, norma e regramento. E, aborda a tecnologia da informação e comunicação (TIC) como suporte as boas práticas de gerenciamento na construção civil, no auxílio a formulação de políticas e gerenciamento de RCD, descreve o sistema de gerenciamento, define algoritmo computacional, linguagem de programação para algoritmos e sistema informatizado de gerenciamento.

\section{Resíduo de Construção e Demolição}

O processo de apropriação de recursos naturais foi acentuado em dois períodos históricos: com o surgimento da moeda e o surgimento da Revolução Industrial. A Revolução Industrial acelerou exponencialmente a geração de resíduos, devido a dinamização dos processos produtivos e ou aumento da produtividade. Iniciativas pontuais de tratamento de resíduos são registradas ao longo da história, como o processamento de entulho de construções em escória de alto-forno, dentre outras ações, ainda no início do século, mas sem o olhar de preservação ambiental (NAGALLI, 2014).

Dessa forma, faz-se necessário o entendimento do que venha a ser Resíduo de Construção e Demolição (RCD), e suas diferenças entre outros termos assemelhados, quais sejam os resíduos sólidos, rejeito e lixo, de acordo com a literatura publicada e normas brasileiras. Para a norma NBR 15112 (ABNT, 2004), que se refere a resíduo volumoso, tem-se que é um resíduo constituído basicamente por material volumoso não removido pela coleta pública municipal, como móveis e equipamentos domésticos inutilizados, grandes embalagens e peças de madeira, podas e outros itens não provenientes de processos industriais. Segundo a norma NBR 1004 (ABNT, 2004), que trata de resíduo sólido, e tem-se a seguinte definição:

Qualquer forma de matéria ou substância no estado sólido ou semissólido, que resulte de atividades industriais, domésticas, hospitalares, comerciais, agrícolas, de serviços e de variação. Ficam incluídos nesta os lodos provenientes do sistema de tratamento de água, 
aqueles gerados em equipamentos e instalações de controle de poluição, bem como determinados líquidos cujas as particularidades tornem inviável o seu lançamento na rede pública de esgotos ou corpos de água, ou exijam para isso soluções técnica e economicamente inviáveis em face a melhor tecnologia disponível.

Nagalli (2014) define lixo como sendo "os restos das atividades considerados pelos geradores como inúteis, indesejáveis ou descartáveis, e que se apresentam, geralmente, em estado sólido, semissólido ou semilíquido". E entulho ou metralha, conhecido como caliça, são resíduos de obras e demolições que formam um conglomerado de diferentes materiais, tornando-se onerosa para o reaproveitamento ou reciclagem, ocasionado pela falta de gerenciamento. A resolução no 307 do Conselho Nacional do Meio Ambiente (CONAMA, 2002) apresenta Resíduo de Construção e Demolição (RCD) como:

[...] provenientes de construções, reformas, reparos e demolições de obras de construção civil, e os resultantes da preparação e da escavação de terrenos, tais como: tijolos, blocos cerâmicos, concreto em geral, solos, rochas, metais, resinas, colas, tintas, madeiras e compensados, forros, argamassa, gesso, telhas, pavimento asfáltico, vidros, plásticos, tubulações, fiação elétrica etc., comumente chamados de entulhos de obras, caliça ou metralha.

\section{Fontes de geração de RCD}

A construção civil nacional caracteriza-se na produção de bens e serviços pelo baixo nível de tecnologia que agrega na sua execução, quando comparado com países de primeiro mundo. Consequentemente, há um consumo intensivo de mão-de-obra e matérias-primas natural e processada (CARVALHO, 2008). Estudos realizados apontam a origem dos RCDs distribuída da seguinte forma: as reformas geram 59\%; os prédios novos geram 21\%; e as residências novas são responsáveis por $20 \%$ da produção de resíduos de construção civil (SUZUKI, 2009).

Com referência ao manejo dos materiais e execução dos serviços de engenharia, Suzuki (2009) especifica os seguintes procedimentos inadequados: mão de obra sem qualificação; o manejo, transporte e armazenamento inapropriado dos materiais; a ineficiência nos mecanismos de controle durante a execução da obra; a falta de processos de reutilização e reciclagem no canteiro de obras; dentre outros fatores. 0 quadro 1 apresenta a associação entre etapas de serviços no desenvolvimento da obra versus perdas ou desperdícios de materiais. Os maiores índices de perdas estão associados aos materiais de gesso, às placas cerâmicas e aos blocos de tijolos, respectivamente, considerando o valor máximo do quadro 1, demonstrando o quanto deve ser perseguido a redução desses resíduos.

Quadro 1: Perdas de materiais x Etapas construtivas.

\begin{tabular}{|c|c|c|c|}
\hline Materiais & \multicolumn{2}{|c|}{ Perda de materiais associadas a etapas de construção (\%) } \\
\hline & Média & Mínimo & Máximo \\
\hline Concreto Usinado & 9 & 2 & 16 \\
\hline Aço & 11 & 4 & 48 \\
\hline Blocos e tijolos & 13 & 3 & 50 \\
\hline Placas Cerâmicas & 14 & 2 & 14 \\
\hline Revestimento têxtil & 14 & 14 & 18 \\
\hline Eletrodutos & 15 & 13 & 56 \\
\hline Tubos para sistemas prediais & 15 & 8 & 24 \\
\hline Tintas & 17 & 8 & 35 \\
\hline Condutores & 27 & 14 & 120 \\
\hline
\end{tabular}

Fonte: Sousa (2005). 


\section{Classificação de RCDs}

A resolução 307/2002 CONAMA, foi o marco no disciplinamento de resíduos de construção civil, este normativo estabeleceu a classificação de resíduos especificamente da área de construção civil, entretanto a NBR 1004/2004 (ABNT) em momento posterior adotou outra classificação de forma mais abrangente para a designação, mas somente resíduos. Os quadros 2 e 3 sintetizam essas classificações distintas. As Normas Brasileiras, expostas nos quadros 2 e 3, foram seguidas e observadas no levantamento dos requisitos e elaboração de documentação do algoritmo do sistema de gerenciamento.

Quadro 2: Classificação de Resíduos de acordo com NBR 1004/2004.

\begin{tabular}{|c|l|}
\hline Classificação & \multicolumn{1}{|c|}{ Características } \\
\hline Classe I-Perigosos & $\begin{array}{l}\text { Aqueles que em função das propriedades físicas, químicas ou infectocontagiosas podem } \\
\text { apresentar riscos à saúde pública ou ao meio ambiente, ou ainda apresentem } \\
\text { características de inflamabilidade, corrosividade, reatividade, toxicidade ou } \\
\text { patogenicidade. }\end{array}$ \\
\hline Classe II A - não inertes & Aqueles que não se enquadram na classificação de perigosos e nem na de inertes \\
\hline Classe II B - inertes & $\begin{array}{l}\text { Aqueles que em contato com água destilada ou deionizada não tiverem nenhum de seus } \\
\text { constituintes solubilizados a concentração superiores aos padrões de potabilidade de } \\
\text { água, à exceção dos padrões de aspecto, cor, turbidez e sabor - contato estático ou } \\
\text { dinâmico, à temperatura ambiente e conforme teste de solubilização segundo a NBR } \\
1006 .\end{array}$ \\
\hline
\end{tabular}

Fonte: ABNT (2004).

Quadro 3: Classificação de RCD de acordo com a Resolução CONAMA 307/2002 com alterações.

\begin{tabular}{|c|c|c|}
\hline Classificação & Características & Exemplos de Resíduos \\
\hline Classe A & $\begin{array}{l}\text { São os resíduos reutilizáveis ou recicláveis como } \\
\text { agregados. }\end{array}$ & $\begin{array}{l}\text { De construção, demolição, reformas e reparos de } \\
\text { pavimentação e de outras obras de infraestrutura, } \\
\text { inclusive solos provenientes de terraplanagem; } \\
\text { De construção, demolição, reformas e reparos de } \\
\text { edificaçães: componentes cerâmicos (tijolos, blocos, } \\
\text { telhas, placas de revestimento etc.), argamassa e } \\
\text { concreto; } \\
\text { De processo de fabricação e/ou demolição de peças } \\
\text { pré-moldadas em concreto (blocos, tubos, meios-fios } \\
\text { etc.) produzidas nos canteiros de obras. }\end{array}$ \\
\hline Classe B & $\begin{array}{l}\text { São os resíduos recicláveis para outras destinações, tais } \\
\text { como plásticos, papel, papelão, metais, vidros, } \\
\text { madeiras, embalagens vazias de tintas imobiliárias e } \\
\text { gesso; (Redação dada pela Resolução no } 469 / 2015 \text { ) }\end{array}$ & Plásticos, papel/papelão, metais, vidros, madeira. \\
\hline Classe C & $\begin{array}{l}\text { São os resíduos para os quais não foram desenvolvidas } \\
\text { tecnologias ou aplicações economicamente viáveis que } \\
\text { permitam a sua reciclagem ou recuperação; (Redação } \\
\text { dada pela Resolução } n^{\circ} 431 / 11 \text { ). }\end{array}$ & Massa corrida, massa de vidro. \\
\hline Classe D & $\begin{array}{l}\text { São resíduos perigosos oriundos do processo de } \\
\text { construção, tais como tintas, solventes, óleos e outros } \\
\text { ou aqueles contaminados ou prejudiciais à saúde } \\
\text { oriundos de demolições, reformas e reparos de clínicas } \\
\text { radiológicas, instalações industriais e outros, bem } \\
\text { como telhas e demais objetos e materiais que } \\
\text { contenham amianto ou outros produtos nocivos à } \\
\text { saúde. (Redação dada pela Resolução } n^{\circ} 348 / 04 \text { ). }\end{array}$ & $\begin{array}{l}\text { Tintas, solventes, óleos e outros, ou os contaminados } \\
\text { oriundos de demolição, reforma e reparos de clínicas } \\
\text { radiológicas, instalações industriais e outros. }\end{array}$ \\
\hline
\end{tabular}

\section{Gestão e gerenciamento de RCD}

A gestão é um processo amplo e compõe-se de políticas, leis e regulamentos que norteiam e direcionam a atuação dos agentes envolvidos no gerenciamento. Os aspectos do gerenciamento dos RCDs em obras civis têm o intuito de assegurar a correta gestão dos resíduos, auxiliando no desenvolvimento das 
atividades de execução dos serviços de engenharia e obras (NAGALLI, 2014). A resolução CONAMA 307/2002 definiu gerenciamento de resíduos de construção civil como:

[...] conjunto de ações exercidas, direta ou indiretamente, nas etapas de coleta, transporte, transbordo, tratamento e destinação final ambientalmente adequada dos resíduos sólidos e disposição final ambientalmente adequada dos rejeitos, de acordo com plano municipal de gestão integrada de resíduos sólidos ou com plano de gerenciamento de resíduos sólidos, exigidos na forma da Lei № 12.305, de 2 de agosto de 2010.

Nagalli (2014) aponta os atores envolvidos no processo de gerenciamento de RCD, e responsáveis pela eficiência dos procedimentos. São eles: Geradores de RCD, transportadores, destinatários e fornecedores. Em lado externo aos procedimentos estão os agentes licenciadores e de fiscalização, auditores, consultor, pesquisadores e clientes.

\section{Sistema informatizado de gerenciamento de RCD}

O fluxo das informações geradas pela documentação de um processo operacional, e ao mesmo tempo, o registro dessas informações, devem ser facilitados pelo uso da tecnologia da informação. Dessa forma, necessita-se de Sistema de Informação Computacional (SI) que auxiliem a captura e o tratamento dos dados do processo operacional.

Um SI pode ser definido como um grupo de componentes que se relaciona objetivando a coleta, o processamento, o armazenamento e a distribuição da informação para dar suporte à alguma tomada de decisão e no controle organizacional (LAUDON, 2011). Desse modo, entendemos que um Sistema de Informação depura dados brutos em informações de utilidade para a finalidade operacional ou de gestão da empresa.

\section{Classificação de sistema de informação}

A classificação de Sistema de Informação (SI) não é uma conceituação rígida, pois se adapta a cada requisito ou condições do negócio, sendo essa classificação muitas vezes denominada pela própria empresa ou organização que utiliza o SI. Apresentamos abaixo as classificações de acordo com a literatura reconhecida sobre alguns sistemas de informação, conforme apresentado no quadro 4.

Quadro 4: Conceitos sistema de informação.

\begin{tabular}{|c|c|l|}
\hline Autor & $\begin{array}{c}\text { TIPO DE SISTEMA DE } \\
\text { INFORMAÇÃO (SI) }\end{array}$ & \multicolumn{1}{c|}{ Conceito/Definição } \\
\hline O'Brien (2001) & $\begin{array}{c}\text { Sistema de } \\
\text { Informação } \\
\text { Operacional (SIO) }\end{array}$ & $\begin{array}{l}\text { Processa as informações e transações rotineiras da empresa, podendo incluir } \\
\text { também os respectivos procedimentos. O SIO processa eficientemente } \\
\text { transações, controla processos industriais, apoia a comunicação e colaboração } \\
\text { dentro da empresa. }\end{array}$ \\
\hline Rezende (2011) & $\begin{array}{c}\text { Sistema de } \\
\text { Informação } \\
\text { Estratégico (SIE) }\end{array}$ & $\begin{array}{l}\text { Neste tipo de sistema as informações são tratadas de modo a permitir que a } \\
\text { alta gestão da empresa possa tomar decisões estratégica de acordo com o } \\
\text { refinamento dos dados, fornecendo gráficos, relatórios dentre outras } \\
\text { requeridas. }\end{array}$ \\
\hline O'Brien (2001) & $\begin{array}{c}\text { Sistema de } \\
\text { Informação } \\
\text { Gerencial (SIG) }\end{array}$ & $\begin{array}{l}\text { O Sistema de Informações Gerenciais difere-se do SIE pelo nível hierárquico de } \\
\text { utilização do usuário, neste caso os usuários são gerentes que necessitam de } \\
\text { dados para tomar as decisões }\end{array}$ \\
\hline Piper et al. (2000) & $\begin{array}{c}\text { Sistema de } \\
\text { Informação } \\
\text { Ambiental (SAI) }\end{array}$ & $\begin{array}{l}\text { Um SIA deve auxiliar na tomada de decisão ambiental além de incentivar a } \\
\text { interação entre os atores envolvidos ambientalmente. }\end{array}$ \\
\hline
\end{tabular}


A engenharia de software aplicada ao Sistema de Informação Ambiental de gerenciamento de RCD (SIA GRCD)

O campo de atuação da engenharia de software é vasto, pois é uma disciplina que se ocupa de todos os aspectos relativos à produção de software, que perpassa desde os estágios iniciais de especificação de sistema até a entrega e a manutenção do mesmo (SOMMERVILLE, 2005). Segundo Pressman (2006), conhecer um modelo de processo que descreva os procedimentos da organização é de fundamental importância, estruturando atividades do processo operacional em suas respectivas fases, bem como a definição da interrelação entre essas. Os modelos de desenvolvimento de software, de acordo com o ciclo de vida do processo organizacional são: Modelo Sequencial Linear, ilustrado na figura 1. Nesse a abordagem o desenvolvimento é sequencial no desenvolvimento do software, denomina-se de modelo em cascata ou ciclo de vida clássico (PRESSMAN, 2006).

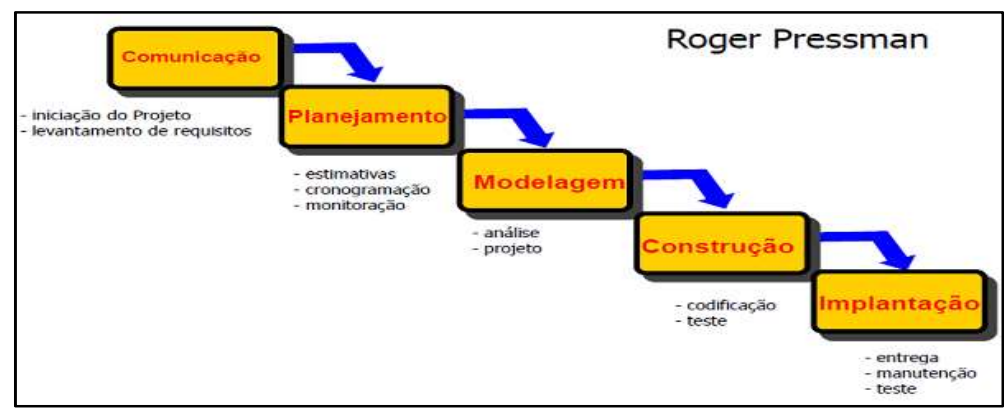

Figura 1: Modelo de desenvolvimento de software em cascata. Fonte: Sousa (2015).

Modelo de desenvolvimento em V, trata-se de um modelo de desenvolvimento de software onde procura-se estreitar as relações entre as atividades de teste (unidade, integração, sistema e teste de aceitação) e as demais fases do processo. Em uma variação do modelo sequencial, de acordo com Pressman (2006) e que foi ilustrado pela figura 2.

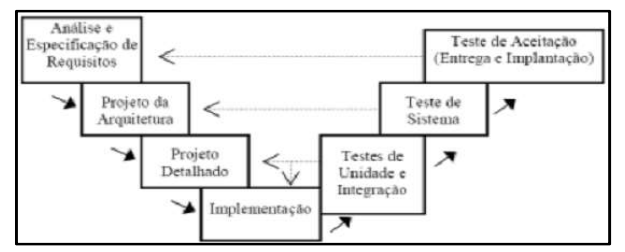

Figura 2: Modelo de desenvolvimento de software V. Fonte: Sousa (2015).

Além dos já propostos e ilustrados anteriormente temos mais dois: o Modelo de Prototipagem; e o Modelo RAD (Rapid Application Development). Neste trabalho adotou-se o desenvolvimento do levantamento dos requisitos, que faz parte da comunicação, e análise do projeto com a respectiva modelagem do algoritmo do sistema de gerenciamento de RCD. As outras fases do desenvolvimento serão tratadas em trabalhos futuros, conforme interesses acadêmico e comercial do Sistema de Informação Ambiental de Gerenciamento de RCD (SIA-GRCD). Esta é a fase mais importante no desenvolvimento de software, sem ela, as demais não existirão. 


\section{Algoritmo computacional para Sistema de Gerenciamento de RCD (SIA -GRCD): aspectos técnicos}

O funcionamento de um computador eletrônico é dependente da sua programação, e o processo de programação é uma conversa controlada entre o ser humano e o computador. Esse processo de comunicação se faz com o uso da linguagem de programação que deve ser interpretada e entendida pela máquina. As linguagens de máquinas, são de baixo e alto nível, sendo que as de alto nível possibilitam maior comunicação com o computador, pelo fato de serem próximos a comunicação humana, pois baseiam-se em códigos entendidos pelos humanos.

Destaca-se, entre as linguagens de alto nível, a FORTRAN, COBOL, BASIC, PASCAL, C, JAVA, Lua, C++, entre outras. Enquanto as linguagens de baixo nível, conhecidas como linguagem de máquinas, são de grande dificuldade e entendimento para os humanos, como exemplo temos a assembly (MANZANO, 2010). É necessário o entendimento de algoritmo computacional: para que serve? Como utilizá-lo? De que forma deve ser escrito? Para trazer esse entendimento, apresentamos sucintamente as principais definições de algoritmo computacional, conforme o quadro 5.

Quadro 5: Conceitos de algoritmo computacional.

\begin{tabular}{|c|l|}
\hline Autor & \multicolumn{1}{c|}{ Conceito/Definição } \\
\hline Manzano (2010) & $\begin{array}{l}\text { Conjunto de regras sequenciais e bem definidas a partir do entendimento lógico de um } \\
\text { problema a ser resolvido por um programador com o objetivo de transformá-lo em um } \\
\text { programa que seja possivel ser tratado e executado por um computador. }\end{array}$ \\
\hline Berg et al. (1998) & É um processo sistemático para a resolução de um problema. \\
\hline Berlinsk & $\begin{array}{l}\text { Algoritmo é um método finito, escrito em um vocabulário simbólico fixo, regido por instruções } \\
\text { precisas que se movem em passos discretos, 1, 2, 3..., cuja execução requer inght, esperteza, } \\
\text { intuição, inteligência, ou clareza e lucidez, que mais cedo ou mais tarde chega ao fim. }\end{array}$ \\
\hline Forbellone et al. (2000) & $\begin{array}{l}\text { Conjunto de regras formais para obtenção de um resultado ou solução de um problema, } \\
\text { englobando fórmulas de expressões aritméticas ou lógicas de programação. }\end{array}$ \\
\hline
\end{tabular}

Ainda segundo Manzano (2010), o desenvolvimento do projeto lógico de um sistema é idealizado e utiliza ferramentas gráficas e/ou textuais. As ferramentas gráficas são denominadas diagrama de blocos, conforme a norma ISO 5807:1985. O modelo de codificação textual de um programa pode ser usado na técnica chamada PDL (Program Design Language), na literatura brasileira denomina-se Português Estruturado, que nada mais é do que uma linguagem de projeto de programação, esta serve como documentação do software.

Portanto, o projeto lógico é a parte de desenvolvimento de software idealizado utilizando ferramentas gráficas e textuais. A linguagem textual utilizada no desenvolvimento do SIA-GRCD foi o Português Estruturado. $\mathrm{O}$ uso desta linguagem possibilita demonstrar de forma concreta a linha de raciocínio lógico no desenvolvimento do programa.

\section{Modelagem do processo de gerenciamento de RCD}

Cerqueira (2007) afirma que a modelação de um processo de negócio é um conjunto de atividades ordenadas englobando os atores responsáveis pelas ações dentro do processo de forma a abstrair e modelar o trabalho da organização ou da empresa. O propósito da modelagem é fornecer uma visão global do negócio ou do processo em análise. Sem a modelagem, a identificação do processo ou negócio torna-se dispendiosa, 
devido à complexidade e as inúmeras informações que envolve o procedimento. Desse modo, a modelagem do negócio provisiona uma visão de fácil entendimento da composição dos processos que compõe o negócio. A mesma possibilita comunicar e documentar as atividades analisadas e compreendê-las.

\section{Linguagem de Modelagem Unificada - UML}

Na modelagem de processos são utilizadas linguagem de diagramação com o objetivo de especificar, visualizar e documentar os modelos de sistema de software orientados a objetos, dentre essas, destaca-se a Linguagem Unificada de Modelagem (UML) voltada ao desenvolvimento de modelos de sistemas de software orientados a objetos, a UML foi desenvolvida pela Object Mangement Group - OMG (VALENTE, 2007).

Santos (2009) afirma que especificar, documentar, visualizar e construir modelos e diagramas de software é recomendável o uso da UML, pois inclui desde os $\mathrm{Sl}^{\prime}$ a serem projetados até às aplicações web e sistemas complexos. A especificação e modelagem do SIA-GRCD foi desenvolvida nos diagramas caso de uso e de classe, os dois pertencentes a linguagem UML.

\section{METODOLOGIA}

O método de pesquisa consiste em um conjunto de regras e procedimentos aceitos pela comunidade acadêmica, para a construção do conhecimento científico (ANDERY, 2012). A área de estudo no campo desse trabalho foi desenvolvida em canteiros de obras localizados nos Municípios de Porto Nacional e Palmas, cidades pertencentes ao Estado do Tocantins, conforme o quadro 6.

Quadro 6: Metodologia e caracterização das áreas de estudos: canteiros de obras.

\begin{tabular}{|c|c|c|c|c|}
\hline \multirow[b]{2}{*}{ Obra } & \multicolumn{4}{|c|}{ Metodologia } \\
\hline & $\begin{array}{l}\text { Frequência de } \\
\text { visitas }\end{array}$ & Atividades realizadas & Local & Caracterização \\
\hline $\begin{array}{c}\text { Residência - } \\
154 \mathrm{~m}^{2}\end{array}$ & $\begin{array}{l}\text { Visitas } \\
\text { realizadas uma } \\
\text { vez por semana }\end{array}$ & $\begin{array}{l}\text { Observação do processo construtivo da } \\
\text { edificação, sem interferência no mesmo; } \\
\text { Relatório fotográfico do canteiro de obra e } \\
\text { das etapas construtivas; } \\
\text { Identificação do processo de }\end{array}$ & $\begin{array}{c}\text { Porto } \\
\text { Nacional } \\
\text { (TO) }\end{array}$ & $\begin{array}{l}\text { Obra residencial térrea, em } \\
\text { bloco cerâmico, } \\
\text { revestimento argamassado, } \\
\text { cobertura de madeira e telha } \\
\text { de concreto }\end{array}$ \\
\hline $\begin{array}{c}\text { Edifício público } \\
\text { - Auditório - } \\
\text { área construída } \\
650 \mathrm{~m}^{2}\end{array}$ & $\begin{array}{l}\text { Visitas } \\
\text { realizadas uma } \\
\text { vez por semana }\end{array}$ & $\begin{array}{l}\text { gerenciamento de RCDs associado a cada } \\
\text { etapa construtiva (Fundação, } \\
\text { superestrutura, vedação e revestimentos); } \\
\text { Registro do fluxo dos processos } \\
\text { construtivos envolvidos em cada etapa da } \\
\text { obra anotando os procedimentos adotados } \\
\text { Análise da planilha orçamentária e o } \\
\text { memorial descritivo da obra; } \\
\text { Analise de contratos de transporte de RCDs; } \\
\text { Analise da logística de requisição e } \\
\text { acondicionamento de materiais para a }\end{array}$ & $\begin{array}{c}\text { Porto } \\
\text { Nacional } \\
\text { (TO) }\end{array}$ & $\begin{array}{l}\text { Obra pública - Auditório - } \\
\text { Localizado no Campus Porto } \\
\text { Nacional do Instituto Federal } \\
\text { do Tocantins. Caracterizada } \\
\text { por pavimento térreo, com } \\
\text { vedação em bloco cerâmico, } \\
\text { revestimento argamassado } \\
\text { externo e interno, estrutura } \\
\text { metálica da cobertura e } \\
\text { telha acústica com } \\
\text { revestimento de zinco. }\end{array}$ \\
\hline $\begin{array}{l}\text { Edifício } \\
\text { comercial com } \\
\text { múltiplos } \\
\text { pavimentos - } \\
\text { área construída } \\
8.600 \mathrm{~m}^{2}\end{array}$ & $\begin{array}{l}\text { Visitas } \\
\text { realizadas } \\
\text { quinzenalmente }\end{array}$ & obra; & $\begin{array}{l}\text { Palmas } \\
\text { (TO) }\end{array}$ & $\begin{array}{l}\text { Edificação com subsolo } \\
\text { térreo e quatro pavimentos. } \\
\text { Vedação em bloco cerâmico, } \\
\text { revestimento argamassado, } \\
\text { cobertura impermeabilizada, } \\
\text { esquadrias em vidros } \\
\text { temperados e divisão interna } \\
\text { em paredes drywall. }\end{array}$ \\
\hline
\end{tabular}




\section{Técnicas de coleta e análise de dados}

A definição de um planejamento de coleta de dados e análise destes dados está intrinsecamente relacionada a questão da pesquisa (LIBRELATO, 2012). Em função disso, as técnicas de coleta e análise de dados é de extrema importância para garantir a operacionalização da pesquisa e os trabalhos definidos pelo pesquisador. Apresentam-se as múltiplas técnicas de coleta e análise de dados para a concepção do modelo de algoritmo e suas respectivas metodologias, de acordo com o quadro 7.

Quadro 7: Metodologia das técnicas de coleta e análise de dados utilizadas.

\begin{tabular}{|l|l|l|}
\hline Ação & Técnicas & Pesquisa \\
\hline \multirow{4}{*}{$\begin{array}{l}\text { Coleta de } \\
\text { Dados }\end{array}$} & $\begin{array}{l}\text { Análise da planilha orçamentária e Memorial descritivo das obras pesquisadas. } \\
\text { Esta pesquisa teve o objetivo de verificar se existia planilha com quantitativo } \\
\text { detalhado de serviços e suas respectivas descrições. }\end{array}$ \\
\cline { 2 - 3 } & Bibliográfica & $\begin{array}{l}\text { Pesquisa na bibliografia específica em contato direto com o desenvolvimento do } \\
\text { modelo }\end{array}$ \\
\cline { 2 - 3 } & Entrevista Verbal & $\begin{array}{l}\text { Conversação com os atores (mestre de obras, empreiteiros, gerentes) envolvidos } \\
\text { na construção civil e sobre os processamentos gerenciamento de RCD. }\end{array}$ \\
\cline { 2 - 3 } & Observação Direta & $\begin{array}{l}\text { O observador identificou determinadas características do processo construtivo e } \\
\text { geração de RCD adotando a técnica de realizando as anotações observadas e com } \\
\text { os devidos relatórios fotográficos. }\end{array}$ \\
\hline \multirow{2}{*}{$\begin{array}{l}\text { Análise de } \\
\text { Dados } \\
\text { e }\end{array}$} & Técnicas \\
$\begin{array}{l}\text { Projeto do } \\
\text { Software }\end{array}$ & $\begin{array}{l}\text { Levantamento dos } \\
\text { requisitos }\end{array}$ & $\begin{array}{l}\text { Para o entendimento do negócio e levantamento dos requisitos foi aplicada a } \\
\text { técnica role playing ou etnografia. }\end{array}$ \\
\cline { 2 - 3 } & $\begin{array}{l}\text { Análise do Processo e } \\
\text { projeto do algoritmo }\end{array}$ & $\begin{array}{l}\text { Com os dados obtidos da etapa levantamento de requisitos fez-se um estudo } \\
\text { minucioso dos requisitos e definiu as melhorias a ser implementada no processo } \\
\text { construtivo de serviços de engenharia de forma a utilizar de forma racional os } \\
\text { insumos, como consequência gerando a menor quantidade de RCD a ser gerido } \\
\text { pelo executor. Nesta etapa foi utilizado os diagramas de caso de uso e de classe } \\
\text { da UML. }\end{array}$ \\
\hline
\end{tabular}

Fonte: Dresch et al. (2015).

Segundo Leffingwell et al. (2000), a técnica de etnografia ou role playing torna-se importante em processos onde o usuário ou gerente não consegue identificar ou transmitir com clareza às informações necessárias para o levantamento dos requisitos. Esta técnica consiste em observar o usuário ou processo analisado no seu cotidiano, ou seja, o observador anota todos os passos do processo sem ocasionar nenhuma interferência ao procedimento.

A análise do processo e o desenvolvimento do projeto do algoritmo computacional foi desenvolvido em escritório com o auxílio de computador pessoal e a utilização do software editor de diagrama DIA versão 0.97.2 e a especificação dos requisitos e suas funcionalidades foi efetivada em processador de texto da MSWORD.

\section{RESULTADOS E DISCUSSÃO}

A observação direta aos canteiros de obras, já especificados, avaliou os processos sob o foco da racionalização de materiais e métodos construtivos e os procedimentos quanto a produção e a gestão de $R C D$, os resultados obtidos estão dispostos no quadro 8. Do quadro 8 , conclui-se que não há controle informatizado nas obras pesquisadas e conforme observado a gestão ocorre de forma empírica, com requisição e controle de materiais e insumos sem o menor controle de produção, acondicionamento e armazenamento. 
Em todas as etapas analisadas houve a geração de RCD. Entretanto, não houve tratamento e nem segregação dos mesmos, sendo formada a caliça de obras e retiradas para aterro municipal sem controle de transporte ambiental. Em trabalhos futuros poderá ser detalhado o quantitativo dos principais resíduos gerados em cada etapa construtiva.

Quadro 8: Resultados da observação direta nos canteiros de obras.

\begin{tabular}{|c|c|c|c|c|c|c|}
\hline \multirow[t]{2}{*}{ OBRA } & \multicolumn{2}{|l|}{ COLETA DOCUMENTAL } & \multirow{2}{*}{$\begin{array}{l}\text { ETAPAS } \\
\text { CONSTRUTIVAS }\end{array}$} & \multicolumn{2}{|c|}{$\begin{array}{l}\text { MÉTODOS } \\
\text { CONSTRUTIVO }\end{array}$} & \multirow{2}{*}{$\begin{array}{l}\text { GEROU/TRATOU } \\
\text { RCD } \\
\text { Sim/não }\end{array}$} \\
\hline & PLANEJAMENTO & POSSUI & & $\mathbf{C}^{1}$ & $\mathbf{R}^{2}$ & \\
\hline \multirow{7}{*}{$\begin{array}{l}\text { Residência } \\
\text { Térrea } \\
154 \mathrm{~m}^{2}\end{array}$} & $\begin{array}{l}\text { Projeto } \\
\text { Gráfico }\end{array}$ & Sim & Fundação & Sim & Não & Sim/não \\
\hline & Planilha orçamentária & & Infraestrutura & Sim & Não & Sim/não \\
\hline & $\begin{array}{l}\text { analítica, sintética } \\
\text { composição de insumos. }\end{array}$ & Sim & \multirow{2}{*}{ Superestrutura } & \multirow[t]{2}{*}{ Sim } & \multirow[t]{2}{*}{ Não } & \multirow{2}{*}{ Sim/não } \\
\hline & Memorial descritivo & Não & & & & \\
\hline & \multirow[t]{2}{*}{ Plano de gestão de RCD } & \multirow[b]{2}{*}{ Não } & Vedação & Sim & Não & Sim/não \\
\hline & & & \multirow[b]{2}{*}{ Cobertura } & \multirow[b]{2}{*}{ Sim } & \multirow[b]{2}{*}{ Não } & \multirow[b]{2}{*}{ Sim/não } \\
\hline & $\begin{array}{l}\text { Gestão e controle da Obra } \\
\text { Informatizada }\end{array}$ & Não & & & & \\
\hline \multirow{5}{*}{$\begin{array}{l}\text { Edifício } \\
\text { público - } \\
\text { Auditório - } \\
\text { área } \\
\text { construída } \\
650 \mathrm{~m}^{2}\end{array}$} & $\begin{array}{l}\text { Projeto } \\
\text { Gráfico }\end{array}$ & Sim & Fundação & Sim & Não & Sim/não \\
\hline & $\begin{array}{l}\text { Planilha orçamentária } \\
\text { analítica, sintética e } \\
\text { composição de insumos. }\end{array}$ & Sim & Infraestrutura & Sim & Não & Sim/não \\
\hline & Memorial descritivo & Não & Superestrutura & Sim & Não & Sim/não \\
\hline & Plano de gestão de RCD & Não & Vedação & Sim & Não & Sim/não \\
\hline & $\begin{array}{l}\text { Gestão e controle da Obra } \\
\text { Informatizada }\end{array}$ & Não & Cobertura & Não & Sim & Sim/não \\
\hline \multirow{6}{*}{$\begin{array}{l}\text { Edifício } \\
\text { comercial } \\
\text { com } \\
\text { múltiplos } \\
\text { pavimentos - } \\
\text { área } \\
\text { construída } \\
8.600 \mathrm{~m}^{2}\end{array}$} & $\begin{array}{l}\text { Projeto } \\
\text { Gráfico }\end{array}$ & Sim & Fundação & Não & Sim & Sim/não \\
\hline & $\begin{array}{l}\text { Planilha orçamentária } \\
\text { analítica, sintética e } \\
\text { composição de insumos. }\end{array}$ & Sim & Infraestrutura & Sim & Não & Sim/não \\
\hline & Memorial descritivo & & Superestrutura & Sim & Sim & Sim/não \\
\hline & Plano de gestão de RCD & Não & Vedação & Sim & Sim & Sim/não \\
\hline & Plano de gestão de RCD & Não & \multirow{2}{*}{ Cobertura } & \multirow{2}{*}{ Não } & \multirow{2}{*}{ Sim } & \multirow[t]{2}{*}{ Sim/não } \\
\hline & $\begin{array}{l}\text { Gestão e controle da Obra } \\
\text { Informatizada }\end{array}$ & Não & & & & \\
\hline
\end{tabular}

\section{Requisitos do SIA-GRCD}

Com base nas observações e dados obtidos nas obras analisadas que serviram como fundamento para o levantamento dos requisitos, gerou-se como resultado um documento de especificação. Neste estão listados os quesitos fundamentais para o desenvolvimento do SIA-GRCD. No documento de especificação de requisitos obtém-se uma visão global do sistema, as principais funcionalidades organizadas em cadastro de obras, cadastro de execução e gerenciamento de RCD, sendo esses os principais módulos do sistema, conforme se apresenta no quadro 9.

\footnotetext{
${ }^{1}$ Método convencional de construção civil que não utiliza técnicas que agregam novas tecnologias e materiais (SOUSA, 2005).

${ }^{2}$ Método Racional de construção utiliza técnicas construtivas que ocasionam menor consumo de insumos e menor impacto ao meio ambiente (SOUSA, 2005).
} 
Quadro 9: Especificação dos requisitos.

\begin{tabular}{|c|c|c|}
\hline \multicolumn{3}{|c|}{ REQUISITOS FUNCIONAIS DO SIA-GRCD } \\
\hline $\begin{array}{l}\text { Cadastrar Usuário } \\
\text { gerente do projeto }\end{array}$ & \multicolumn{2}{|c|}{$\begin{array}{l}\text { Id, nome, endereço, cidade, UF, RG, órgão expedidor, CPF, CTPS (contrato de trabalho), CREA, cargo } \\
\text { gerente (tático, operacional), data de nascimento, sexo, data de ingresso na empresa, telefone, nível } \\
\text { de acesso. }\end{array}$} \\
\hline Cadastrar Obra & \multicolumn{2}{|c|}{$\begin{array}{l}\text { Id, nome, endereço, cidade, UF, quantidade }\left(\mathrm{m}^{2}\right) \text {, Registro CREA, Licença ambiental, data de Início, } \\
\text { data de término, contratante, valor (R\$̦, US\$̦, } € \text { ). }\end{array}$} \\
\hline Cadastrar Serviço & \multicolumn{2}{|c|}{$\begin{array}{l}\text { Id, nome, endereço, cidade, UF, quantidade }\left(\mathrm{m}^{2}\right) \text {, Registro CREA, Licença ambiental, data de Início, } \\
\text { data de término, contratante, valor (R\$, US\$, } € \text { ). }\end{array}$} \\
\hline Cadastrar Demolição & \multicolumn{2}{|c|}{$\begin{array}{l}\text { Id, nome, endereço, cidade, uf, quantidade }\left(\mathrm{m}^{2}\right) \text {, Registro CREA, Licença ambiental, data de Início, data } \\
\text { de término, contratante, valor (R\$, US\$, €). }\end{array}$} \\
\hline $\begin{array}{l}\text { Cadastrar Projeto básico } \\
\text { e executivo - } \\
\text { obra/serviço/ } \\
\text { demolição }\end{array}$ & \multicolumn{2}{|c|}{$\begin{array}{l}\text { Id, nome, etapa, subetapa, item, quantidade, valor unitário (R\$, US\$, €), cronograma(dias), fator de } \\
\text { equipe, fator de cronograma, fator de fiscalização, fator de sobra, fator de recorrência do resíduo }\end{array}$} \\
\hline $\begin{array}{l}\text { Cadastrar equipe de } \\
\text { colaboradores }\end{array}$ & \multicolumn{2}{|c|}{$\begin{array}{l}\text { Id, nome, endereço, cidade, UF, RG, órgão expedidor, CPF, CTPS (contrato de trabalho), CREA, } \\
\text { profissão, data de nascimento, sexo, escolaridade, data de ingresso no projeto, data de ingresso na } \\
\text { empresa, telefone, e-mail, tempo de experiência (CTPS). }\end{array}$} \\
\hline $\begin{array}{l}\text { Cadastrar } \\
\text { acondicionamento e } \\
\text { Armazenamento de RCD }\end{array}$ & \multicolumn{2}{|c|}{$\begin{array}{l}\text { Id, nome, tipo (baia, caçamba, bombonas, sacos, pilhas, outros), tempo (dias), classe (A, B, C, D), } \\
\text { código de cor(Azul, vermelho, Verde, Amarelo, Preto, Laranja, Branco, Roxo, Marrom, Cinza), data da } \\
\text { coleta, local de destino final, autorização ambiental, validade. }\end{array}$} \\
\hline $\begin{array}{l}\text { Cadastrar prestadores } \\
\text { de serviços de } \\
\text { transporte RCD }\end{array}$ & \multicolumn{2}{|c|}{$\begin{array}{l}\text { Id, nome, empresa, endereço, cidade, UF, CNPJ/CPF, inscrição municipal, inscrição estadual, alvará, } \\
\text { telefone, autorização ambiental, validade. }\end{array}$} \\
\hline $\begin{array}{l}\text { Cadastrar programa de } \\
\text { treinamento ambiental }\end{array}$ & \multicolumn{2}{|c|}{$\begin{array}{l}\text { Id, nome, capacitação, ação, uso racional de material, nome do gerente responsável, data de início, } \\
\text { data de término. }\end{array}$} \\
\hline $\begin{array}{l}\text { Relatórios de Cadastro - } \\
\text { Programa de } \\
\text { gerenciamento de RCD }\end{array}$ & \multicolumn{2}{|c|}{$\begin{array}{l}\text { Cadastro usuário } \\
\text { Cadastro da obra/serviço/demolição } \\
\text { Cadastro da equipe colaboradores } \\
\text { Cadastro do acondicionamento e armazenamento } \\
\text { Cadastro de programa de treinamento ambiental }\end{array}$} \\
\hline \multicolumn{3}{|c|}{ REQUISITOS NÃO FUNCIONAIS } \\
\hline Descrição & Restrição & Categoria \\
\hline Controle de acesso & $\begin{array}{l}\text { Usuário deve possuir certificação digital para ter } \\
\text { permissão de acesso ao SIA-GRCD }\end{array}$ & Segurança \\
\hline Compatibilidade & $\begin{array}{l}\text { O sistema deve ser compatível com os navegadores } \\
\text { Mozilla Firefox, Google Chrome, Internet explorer. }\end{array}$ & Portabilidade \\
\hline Navegabilidade & $\begin{array}{l}\text { Usuário deve possuir apenas conhecimento básico de } \\
\text { informática }\end{array}$ & Usabilidade \\
\hline Backup & $\begin{array}{l}\text { O armazenamento de dados devem ser em storage nas } \\
\text { nuvens ou em banco de dados próprios, conforme } \\
\text { dispuser a arquitetura do sistema. }\end{array}$ & Confiabilidade \\
\hline
\end{tabular}

\section{Análise e projeto do SIA-GRCD}

Apresenta-se o diagrama caso de uso da UML, onde é exposto o modelo funcional do SIA-GRCD, neste diagrama demonstra-se as funcionalidades do software na visão do usuário. O diagrama apresenta o operador gerente tático que realiza o cadastro do gerente operacional, por sua vez este fará todas as operações manuais do sistema tais como: Cadastrar as obras, serviços e demolições, associados aos fatores de estimativa e uso racional de RCD. Cadastra ainda os colaboradores (Engenheiro, mestre de obras, pedreiro, dentre outros) com os seus respectivos requisitos, efetiva o cadastramento do treinamento ambiental dentre outros, e por fim o sistema fará o processamento e gerará os relatórios conforme requisição parametrizada. Na figura 3, expõe-se o diagrama de caso de uso do software. 


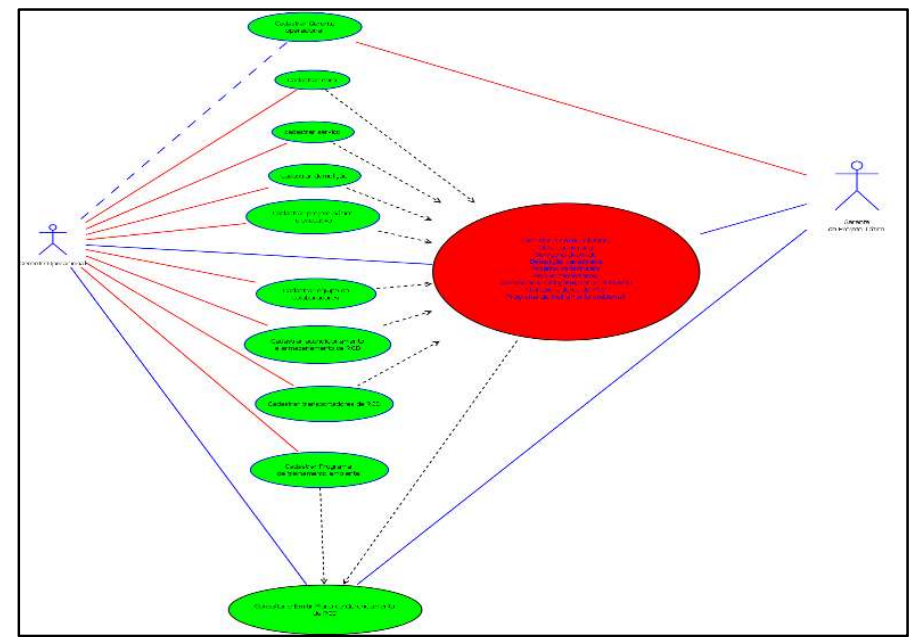

Figura 3: Modelagem do diagrama de caso de uso do SIA-GRCD.

Nessa etapa, há o delineamento do diagrama de classes, onde detalha a estática estrutural da organização, empresa de construção civil, foi detalhado apenas as classes sem atributos e seus respectivos métodos, que serão elaboradas em trabalhos futuros quando da implantação do sistema em modelo de negócio próprio. De acordo com o observado, a figura 4 detalha a estrutura da organização.

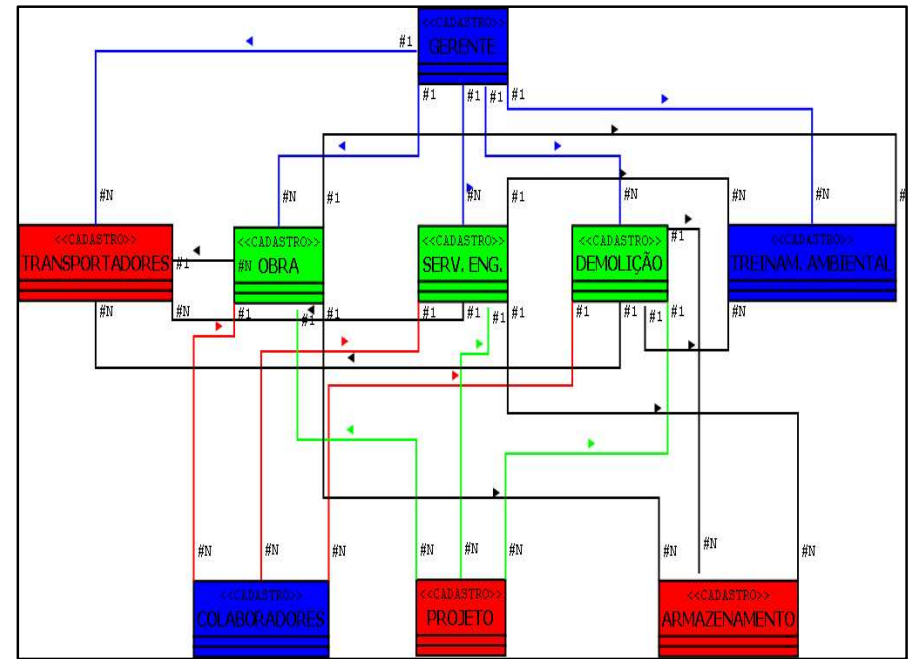

Figura 4: Modelagem do diagrama de classes do SIA-GRCD.

A classe gerente detém a inclusão, exclusão, alteração de dados sobre as classes transportadores, obra, serviço de engenharia, demolição, colaboradores e treinamento ambiental, por sua vez a classe de obras, serviços de engenharia e demolição contém relação com as classes colaboradores, projeto, armazenamento, transportadores e treinamento ambiental, com as respectivas cardinalidades.

\section{Modelagem do algoritmo do projeto do SIA-GRCD}

A modelagem do algoritmo é a última etapa da análise e desenvolvimento do projeto SIA-GRCD, neste foi elaborado o fluxograma de acordo com as funcionalidades do sistema, conforme apresenta-se na figura 5, na qual se traz um fluxograma. Esboçado de forma explicativa, a figura 5 traz uma sequência de passos a serem executados. 


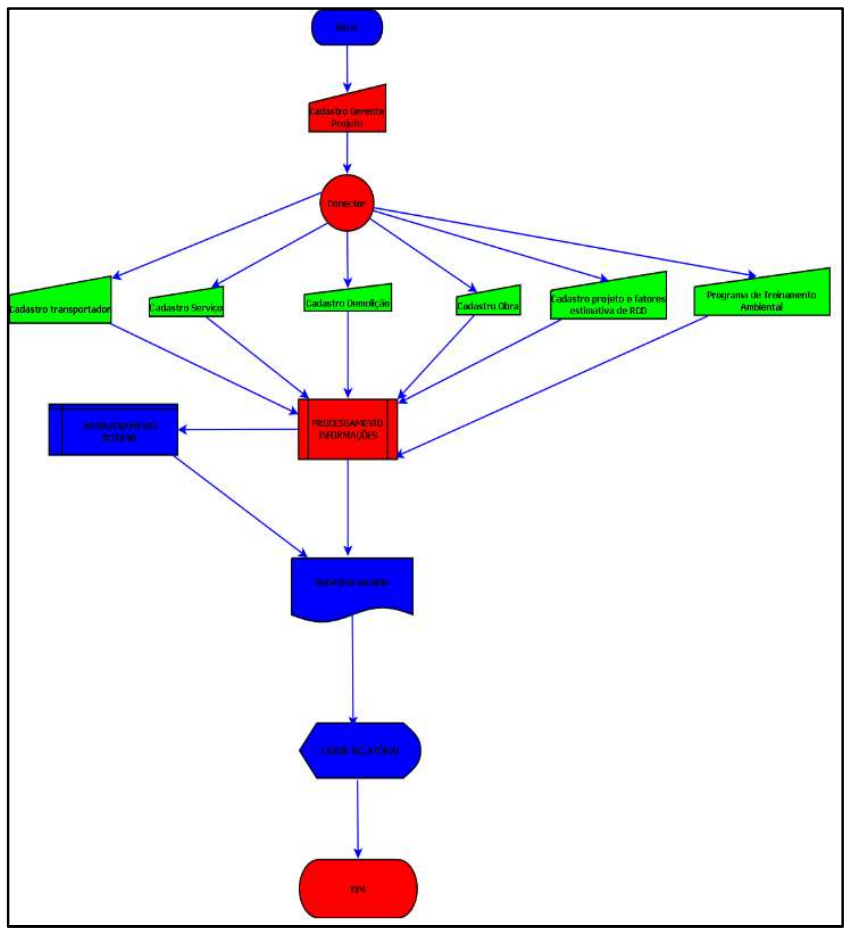

Figura 5: Modelagem do algoritmo do SIA-GRCD.

\section{CONCLUSÕES}

Este artigo apresentou o desenvolvimento de um modelo de algoritmo para o gerenciamento de resíduos de construção civil direcionado às empresas de pequeno porte, neste espera-se contribuições para as áreas acadêmica, de tecnologia da informação, e principalmente, para o campo da sustentabilidade em obras de construção civil no que concerne ao manejo dos resíduos derivados de obras.

$\mathrm{Na}$ área acadêmica, espera-se a contribuição para o desenvolvimento de novos trabalhos de pesquisas envolvendo a sustentabilidade em obras de construção civil, o aprofundamento de outros estudos no tratamento de resíduos de obras, e o desenvolvimento de novas tecnologias que contribuam para o gerenciamento de resíduos de construção e demolição. Para o campo da sustentabilidade ambiental em obras de construção civil, almeja contribuir para a redução do impacto ambiental ocasionado pelos RCDs, devido a implantação de novas tecnologias de gerenciamento.

Com relação ao aspecto prático da implantação nos canteiros de obras, do produto tecnológico derivado dessa pesquisa, será solicitado o registro da patente do modelo de algoritmo computacional para Sistema de Informação Ambiental (SIA) no Instituto Nacional de Propriedade Intelectual (INPI). Após o processo de registro do produto será disponibilizado às empresas de tecnologias que tenham o interesse em estabelecer parceria comercial, no sentido de disponibilizar e comercializar o software de gerenciamento de RCD.

\section{REFERÊNCIAS}

ABNT. Associação Brasileira de Normas Técnicas. NBR 10004: Resíduos sólidos: classificação. Rio de Janeiro: ABNT, 2004.

ABNT. Associação Brasileira de Normas Técnicas. NBR 15112: Resíduos sólidos da construção civil: áreas de transbordo e triagem: diretrizes para projeto, implantação e operação. Rio de Janeiro: ABNT, 2004.

ABNT. Associação Brasileira de Normas Técnicas. NBR 15113: Resíduos sólidos da construção civil e resíduos 
inertes: aterros: diretrizes para projeto, implantação e operação. Rio de Janeiro: ABNT, 2004.

ABNT. Associação Brasileira de Normas Técnicas. NBR 15114: Resíduos sólidos da construção civil: áreas de reciclagem: diretrizes para projeto, implantação e operação. Rio de Janeiro: ABNT, 2004.

ABNT. Associação Brasileira de Normas Técnicas. NBR 15115: Agregados reciclados de resíduos sólidos da construção civil: execução da camada de pavimentação: procedimentos. Rio de Janeiro: ABNT, 2004.

ABNT. Associação Brasileira de Normas Técnicas. NBR 15116: agregados reciclados de resíduos sólidos da construção civil: utilização em pavimentação e preparo do concreto sem função estrutural: requisitos. Rio de Janeiro: ABNT, 2004.

ANDERY, M. A.; MICHELETTO, N.. Para compreender a ciência: uma perspectiva histórica. 16 ed. Rio de Janeiro: Garamond, 2012.

BRASIL. Resolução n.307 de 05 de julho de 2002. Estabelece diretrizes, critérios e procedimentos para a gestão dos resíduos da construção civil. Brasília: MMA, 2002.

CARVALHO, E. M.. Resíduos sólidos da construção civil e desenvolvimento sustentável: modelo de sistema de gestão de Aracaju. Dissertação (Mestrado em Desenvolvimento e Meio Ambiente) - Universidade Federal de Sergipe, São Cristóvão, 2008.

LAUDON, K. C.; LAUDON, J. P.. Gerenciamento de Sistemas de Informação. 3 ed. São Paulo: 2011.
MANZANO, N. G.; OLIVEIRA, J. F.. Algoritmos: lógica para desenvolvimento de programação de computadores. 24 ed. São Paulo: Ética, 2010.

NAGALLI, A.. Gerenciamento de Resíduos Sólidos na Construção Civil. São Paulo: Oficinas de Textos, 2014.

O'BRIEN, J. A.. Sistema de informação e as decisões gerenciais na era da internet. 9 ed. São Paulo: 2001.

PIPER, S.. Premissas para o design conceitual de um Sistema de Informação Ambiental a partir da teoria social do aprendizado. 9 ed. São Paulo: 2000.

PREISS, B. R.. Estrutura de Dados e algoritmos: padrões de projetos orientados com Java. 4 ed. Rio de Janeiro: Elsevier, 2000.

PRESSMAN, R.. Engenharia de Software. São Paulo: McGraw-Hill Brasil, 2006.

REZENDE, D. A.. Planejamento de sistemas de Informação e Informática. São Paulo: Atlas, 2011.

SOMMERVILLE, I.. Engenharia de Software. São Paulo: Pearson Addison Wesley, 2005.

SOUSA, U. E. L.. Como reduzir perdas nos canteiros: manual de gestão do consumo de materiais na Construção Civil. São Paulo: Pini, 2005.

SUZUKI, R. L.. Guia para elaboração de projeto de gerenciamento de Resíduos da Construção Civil. Curitiba: CREA, 2010.

A CBPC - Companhia Brasileira de Produção Científica (CNPJ: 11.221.422/0001-03) detém os direitos materiais desta publicação. Os direitos referem-se à publicação do trabalho em qualquer parte do mundo, incluindo os direitos às renovações, expansões e disseminações da contribuição, bem como outros direitos subsidiários. Todos os trabalhos publicados eletronicamente poderão posteriormente ser publicados em coletâneas impressas sob coordenação da Sustenere Publishing, da Companhia Brasileira de Produção Científica e seus parceiros autorizados. Os (as) autores (as) preservam os direitos autorais, mas não têm permissão para a publicação da contribuição em outro meio, impresso ou digital, em português ou em tradução. 